\title{
Dilated right cardiac chamber delusion solved by cardiovascular magnetic resonance
}

\section{Catarina Costa ${ }^{a}$, Ricardo Pinto ${ }^{a}$, Teresa Pinhob ${ }^{b}$ André Carvalhoc, Cristina Cruza , António Madureirad, Filipe Macedo ${ }^{b}$}

a Department of Cardiology, Centro Hospitalar São João, Porto, Portugal

${ }^{b}$ Department of Cardiology, Centro Hospitalar São João, Porto, Portugal; University of Porto, Faculty of Medicine, Porto, Portugal

' Radiology Department, Centro Hospitalar São João, Porto, Portugal

${ }^{d}$ Radiology Department, Centro Hospitalar São João, Porto, Portugal; University of Porto, Faculty of Medicine, Porto, Portugal

ARTICLE INFO

Article history:

Submitted: 18. 1. 2021

Revised: 7. 3. 2021

Accepted: 8. 3. 2021

Available online: 1. 12. 2021

A previously healthy 59-year-old woman complained of palpitations and breathlessness. Two relatives had sudden cardiac death, including a sibling with dilated cardiomyopathy. Her electrocardiogram showed sinus rhythm and incomplete right bundle branch block. Transthoracic echocardiography (TEE) revealed a dilated right ventricle (RV) with normal systolic function and moderate tricuspid regurgitation (estimated pulmonary artery systolic pressure $45 \mathrm{mmHg}$ ); no other alterations were found.

Suspicion of arrhythmogenic RV cardiomyopathy (ARVC) was raised and a cardiovascular magnetic reso- nance (CMR) was performed. Steady-state free precession CINE images confirmed a dilated RV (indexed end-diastolic volume $159 \mathrm{ml} / \mathrm{m}^{2}$ ), with no regional akinesia or dyskinesia (Fig. 1A and 1B). No focal myocardial fibrosis was detected (Fig. 1C). Phase contrast sequences acquired at the aortic root and pulmonary trunk uncovered a significant left-toright cardiac shunt ( $\mathrm{Qp} / \mathrm{Qs}=2)$. CINE sequences directed to the inter-auricular septum revealed an ostium secundum atrial septal defect (ASD), measuring approximately $13-11 \mathrm{~mm}$ with a shunt of $39 \mathrm{ml}$ (Fig. 2). MR-angiography identified partial anomalous pulmonary venous connec-

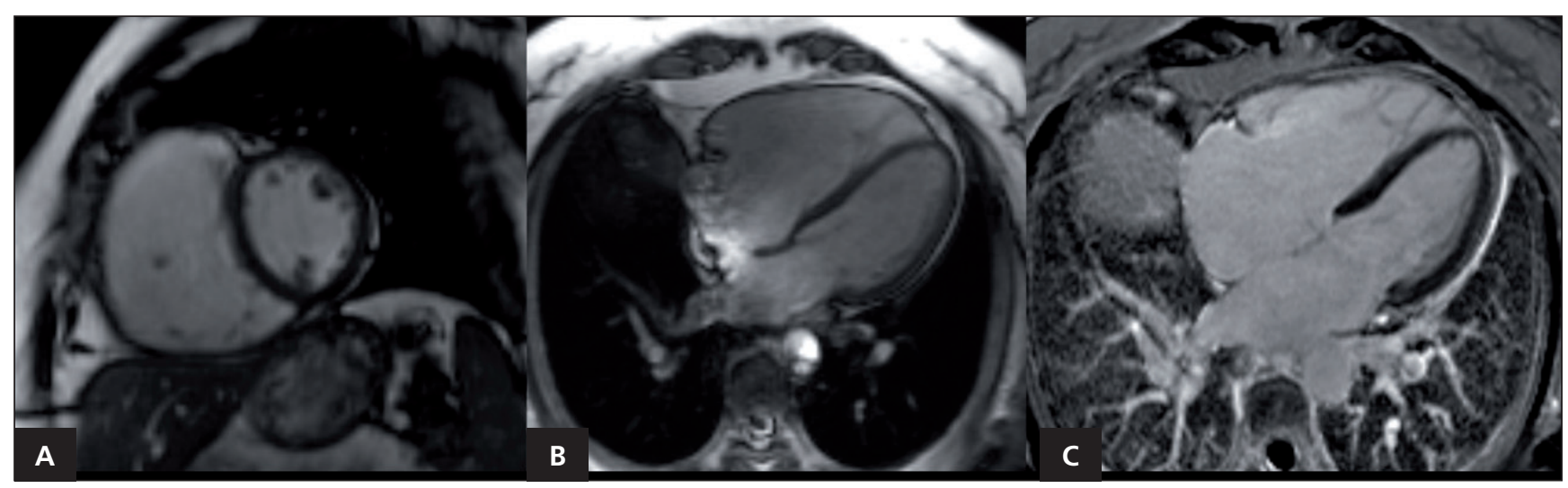

Fig. 1 - CINE imaging in short-axis (A) and horizontal long-axis (B) end-diastolic image frames. Severe dilation of the RV is noted (256 ml; $159 \mathrm{ml} / \mathrm{m}^{2}$ ) without regional akinesia or dyskinesia or systolic dysfunction (EF: $62 \%$ ). Late gadolinium enhancement PSIR imaging (C) shows no evidence of myocardial fibrosis. EF - ejection fraction; PSIR - phase-sensitive inversion recovery; RV - right ventricle.

Address: Catarina Costa, MD, MS, Department of Cardiology, Centro Hospitalar São João, Alameda Prof. Hernâni Monteiro, 4200-319 Porto, Portugal, e-mail: catarinamarcosta@gmail.com

(c) 2021, ČKS. 


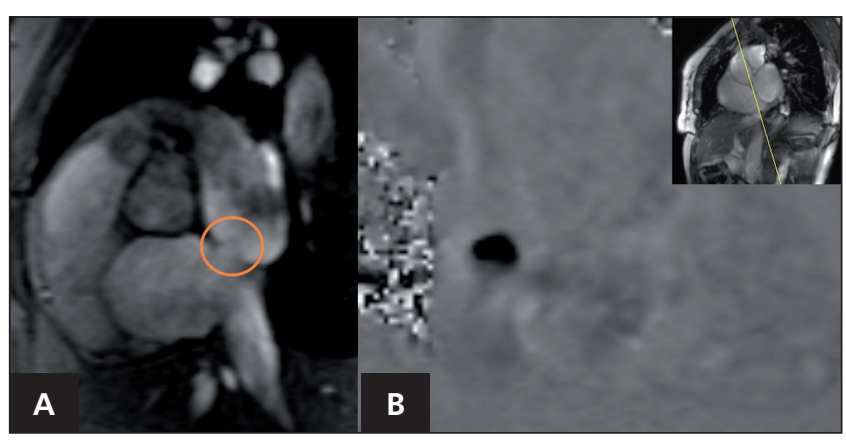

Fig. 2 - CINE imaging in sagittal oblique axis (A) showing an ostium secundum ASD (circle). Through-plane PC-MRI imaging demonstrates significant flow through the ASD. ASD - atrial septal defect; PC-MRI - phase-contrast magnetic resonance imaging. ital heart disease with left-to-right shunting. ${ }^{1}$ When first line echocardiography is equivocal or inconclusive, CMR can provide additional information. ${ }^{2}$ In this particular patient, suggestive findings of anomalous drainage, such as dilated superior vena cava and fewer than four pulmonary veins connecting to the left atrium, were inconspicuous. Moreover, ASD - the most typical finding associated with PAPVC - was also unrecognized.

This clinical case highlights CMR use in the study of dilated right cardiac chambers, and the relevance of a systematic evaluation of Qp/Qs.

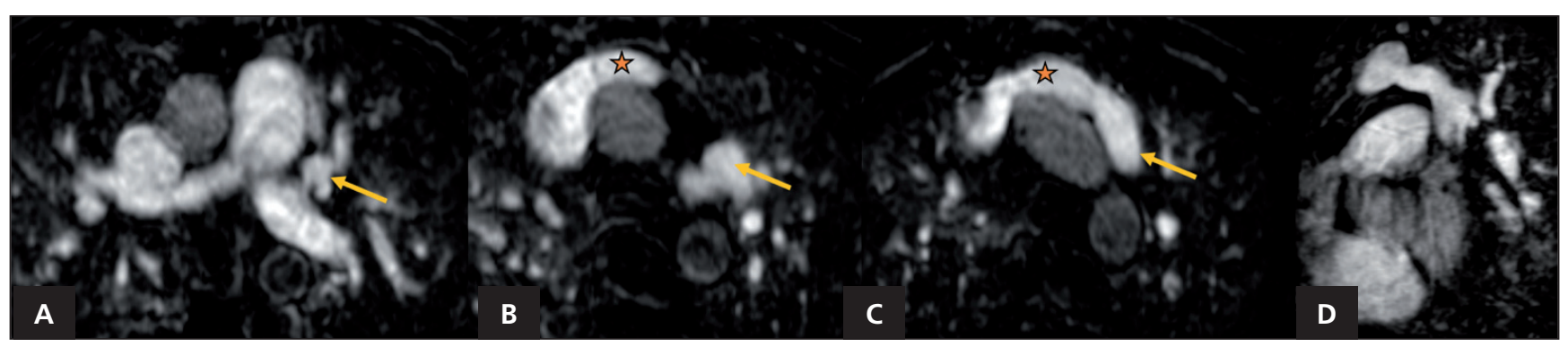

Fig. 3 - MR-angiography imaging in the axial plane (A-C) shows abnormal communication of the left superior pulmonary vein (arrows) to the left brachiocephalic vein (asterisk). Sagittal-oblique MPR (D) showing the partial anomalous pulmonary venous return. MPR - multiplanar reformation.

tion (PAPVC) of the superior left pulmonary vein draining in the left brachiocephalic vein (Fig. 3).

Right chambers dilatation is a common manifestation in several pathologies, namely ARVC and congen-

\section{References}

1. Gandjbakhch E, Redheuil A, Pousse F, et al. Clinical Diagnosis, Imaging, and Genetics of Arrhythmogenic Right Ventricular Cardiomyopathy/Dysplasia. J Am Coll Cardiol 2018;72:784-804.

2. Towbin J, McKenna W, Abrams D, et al. HRS expert consensus statement on evaluation, risk stratification, and management of arrytmogenic cardiomyopathy. Heart Rhythm 2019;16:E301-E372.

3. Liu T, Pursnani A, Sharma U, et al. Effect of the 2010 task force criteria on reclassification of cardiovascular magnetic resonance criteria for arrhythmogenic right ventricular cardiomyopathy. J Cardiovasc Magn Reson 2014;16:47. 